\title{
Imaging of $\beta$-Cell Mass and Function
}

\author{
Masanori Ichise ${ }^{1}$ and Paul E. Harris ${ }^{2}$ \\ ${ }^{I}$ Department of Radiology, Columbia University Medical College, New York, New York; and ${ }^{2}$ Department of Medicine, Columbia \\ University Medical College, New York, New York
}

In both type 1 and type 2 diabetes mellitus, $\beta$-cell mass (BCM), which exclusively produces insulin, is lost. Various therapeutic strategies are being developed that target BCM to restore its function by promoting $\beta$-cell neogenesis and regeneration or by preventing its apoptosis. To this end, it is essential to identify biomarkers of BCM. Of the various imaging platforms, radionuclide-based imaging methods using radioligands that directly target BCM appear promising. In particular, the vesicular monoamine transporter type 2 (VMAT2), which is expressed almost exclusively by $\beta$-cells and found in close association with insulin, can be noninvasively imaged with PET and ${ }^{11} \mathrm{C}$-dihydrotetrabenazine or its derivatives. Despite the major limitation that $\beta$-cells are low in abundance $(1 \%-2 \%)$ and dispersed throughout the pancreas, VMAT2 PET is sensitive enough to detect VMAT2 signal and to allow kinetic model-based quantification of VMAT2 binding within the pancreas. However, these techniques are still in early stages, and careful further evaluations and technical developments are needed before they can be clinically used as a valid biomarker of BCM.

Key Words: diabetes; beta cell mass; VMAT2; pancreas; DTBZ; PET

J Nucl Med 2010; 51:1001-1004

DOI: 10.2967/jnumed.109.068999

Diabetes mellitus is a group of metabolic diseases characterized by hyperglycemia that result from absolute or relative deficits in insulin secretion by $\beta$-cells of the islets of Langerhans in the pancreas. Type 1 diabetes (T1D) is a result of autoimmune destruction of $\beta$-cells. T1D has an insipid onset and may take years before it can be clinically recognized. Most of the $\beta$-cell mass (BCM) in T1D was long thought to be destroyed at the time of presentation with hyperglycemia. However, recent evidence suggests that the BCM may have significant residual insulin-secretory capacity even after a longstanding history of the disease (1).

Type 2 diabetes (T2D), on the other hand, results from multiple metabolic abnormalities including increased hepatic glucose production, impaired insulin secretion, and peripheral

Received Nov. 17, 2009; revision accepted Jan. 11, 2010.

For correspondence or reprints contact: Masanori Ichise, Department of Radiology, Neurological Institute Hatch Center-NI B04L, Columbia University Medical Center, 710 W. 168th St., New York, NY 11032.

E-mail: mi2193@columbia.edu

COPYRIGHT @ 2010 by the Society of Nuclear Medicine, Inc. resistance to insulin. In T2D, the $\beta$-cells over time can no longer meet the increased need for insulin, and BCM declines. Multiple metabolic derangements can exert toxic effects on BCM resulting in up to a $65 \%$ loss in the BCM (2). In North America, diabetic patients usually have T2D. Many destined to develop T2D spend years in a prediabetic condition characterized by impaired fasting glucose levels. As estimated for 1999-2002 by the National Institute of Diabetes and Digestive and Kidney Diseases, 19.3 million individuals were diabetic and an additional 54 million had impaired fasting glucose levels. The prevalence of total diabetic patients rose with age, reaching $21.6 \%$ for those aged $65 \mathrm{y}$ or more. These prevalence estimates reflect America's largest health care epidemic (3).

A variety of experimental treatments for T1D is currently under development, including immunotherapy, stem cell therapy, and islet transplantation. The treatment of T2D has been largely empiric because of the lack of understanding of the basic mechanisms that are at work. However, in both T1D and T2D, significant amounts of BCM are lost. An understanding of how BCM changes during the course of diabetes may provide important information needed for the development of new therapy strategies for T1D and T2D. To this end, it is essential to develop biomarkers of BCM.

\section{SEARCH FOR BIOMARKERS OF $\beta$-CELLS}

A biomarker of $\beta$-cells should allow a better understanding of the pathophysiology of their losses in diabetes. Additionally, a biomarker can be used to gauge the response to treatment that targets these insulin-secreting cells and seeks to restore their function by promoting the neogenesis and regeneration of $\beta$-cells or by preventing their apoptosis. To accomplish this goal, the biomarker needs to be both a trait marker and a state marker of $\beta$-cells. Stimulated insulin secretion capacity is currently used as an indirect measure of BCM. However, insulin secretion measurements are limited not only by their inability to predict the development of diabetes, for which metabolic or inflammatory stress may reversibly compromise $\beta$-cell function without BCM losses, but also by their large intraassay variability (4). Direct invasive $\beta$-cell sampling is technically difficult and not practical. Therefore, no reliable and noninvasive biomarkers of BCM are currently available.

Recognition of the sweet taste of urine in diabetic patients was probably the first metabolomic biomarker of diabetes (5). Effort has recently focused on identifying biomarkers of BCM using proteomics, microRNA profiling, and gene expression profiling. However, such studies are in their infancy. 
Alternatively, the use of in vivo imaging such as MRI and PET has the potential to achieve this end, because it is practical, noninvasive, and carries a minimal risk. MRI can be useful in accurately estimating the pancreatic volume by separating fat. However, $\beta$-cell-containing tissue accounts for only $1 \%-2 \%$ of the pancreas, and MRI cannot distinguish between the exocrine and endocrine pancreas without specific contrast reagents, which must be reacted with islets ex vivo (islet transplantation) (6). Radionuclide-based imaging, on the other hand, allows targeting of certain molecules in tissue. For example, by targeting anion transporters expressed by pancreatic acinar cells, ${ }^{11} \mathrm{C}$-acetate PET can visualize the exocrine pancreas (7). ${ }^{18} \mathrm{~F}$-FDG may be useful in imaging transplanted islets to evaluate their viability $(8)$.

PET has long been used to quantify certain critical components of the neurotransmission system. Clark et al., using ${ }^{18} \mathrm{~F}$-4-fluorobenzyltrozamicol, imaged vesicular acetylcholine transporters on presynaptic neuronal vesicles innervating the pancreas, showing increased ${ }^{18} \mathrm{~F}$-4-fluorobenzyltrozamicol uptake in prediabetic rodent pancreata (9).

To develop $\beta$-cell biomarkers, one must choose target molecules that are specific $\beta$-cells and readily quantifiable by PET. In gene expression profiling experiments to study tissuerestricted transcripts in human islets, our group identified a series of neurofunctional gene products in human $\beta$-cells (10). We selected as a potential PET marker the vesicular monoamine transporter type 2 (VMAT2) that is expressed by $\beta$-cells and monoaminergic neurons but is absent from the exocrine pancreas and other abdominal organs because of the availability of a VMAT2 PET radioligand, ${ }^{11} \mathrm{C}$-dihydrotetrabenazine (DTBZ). ${ }^{11} \mathrm{C}$-DTBZ has been a useful biomarker of brain dopamine neurons (11).

Histochemical evidence suggests that VMAT2 found on vesicles that store insulin and dopamine within $\beta$-cells is independent of insulin synthesis, processing, and secretion $(12,13)$. The function of VMAT2 in $\beta$-cells is similar to that in the central nervous system: control of vesicular monoamine content (Fig. 1). In $\beta$-cells, however, vesicular monoamines (e.g., dopamine) are thought to regulate insulin secretion (14) via other monoamine receptors expressed on neighboring $\beta$-cells (15). Although the concentrations of VMAT2 in the brain (mostly in the striatum) are small ( $~ 800 \mathrm{fmol} / \mathrm{mg}$ of protein), ${ }^{11} \mathrm{C}$-DTBZ PET allows excellent visualization and quantification of specific VMAT2 binding in the striatum (11).

\section{VMAT2 AS A BIOMARKER OF $\beta$-CELLS}

Rodent models of T1D showed that ${ }^{11} \mathrm{C}$-DTBZ uptake in the pancreas correlated well with measures of glucose homeostasis $(16,17)$. Pancreatic VMAT2 binding decreased as the ability to clear glucose from the blood was lost. Since then, some groups have reported similar findings, whereas other groups have reported difficulties in detecting any differences between euglycemic and diabetic rodents (18-20). This inconsistency may be due to problems with identifying the pancreas on smallanimal PET images, radioligands with insufficient specific activity, and the rodent strain and age selection.

Our group extended ${ }^{11} \mathrm{C}$-DTBZ PET of BCM to humans with long-standing T1D and healthy controls as the first proof-of-
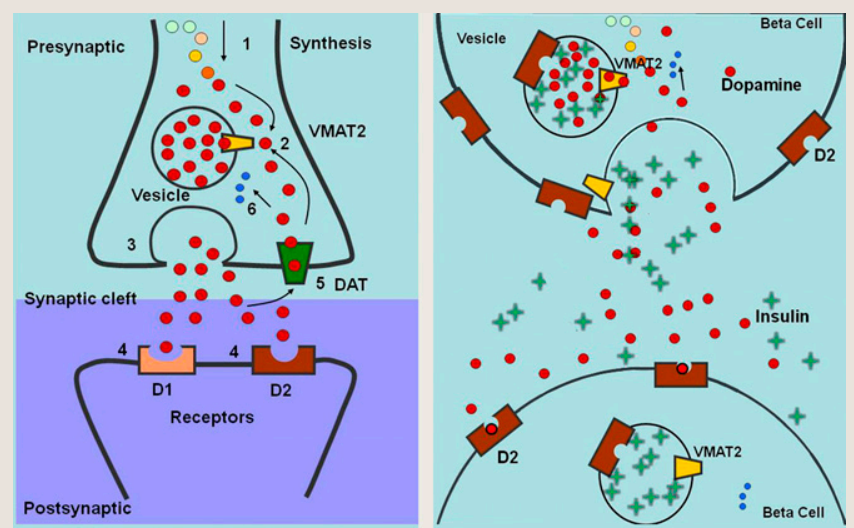

FIGURE 1. Schematic diagrams of VMAT2 in brain and proposed function of VMAT2 in $\beta$-cells of pancreas. (Left) Cytoplasmic dopamine is synthesized (1) and then transported (2) by VMAT2 into presynaptic vesicles and later delivered to synaptic junction by exocytosis (3). Dopamine diffuses across junction and binds to receptors on postsynaptic cell (4). Activated receptors change activity of postsynaptic neuron. Dopamine is also degraded by monoamine oxidase (6) or recycled from synaptic cleft by dopamine transporter (DAT) (5). (Right) VMAT2 transports cytoplasmic dopamine into insulincontaining vesicles. On glucose stimulation, insulin and dopamine are delivered to extracellular space. Dopamine diffuses to neighboring $\beta$-cell and binds to dopamine $D_{2}$ receptor, inhibiting further insulin secretion.

concept clinical study (21). ${ }^{11}$ C-DTBZ PET allowed excellent visualization of the pancreas (Fig. 2) and kinetic model-based quantification of VMAT2 binding. In controls, VMAT2 binding correlated well with stimulated insulin secretion. The functional VMAT2 binding capacity (defined as VMAT2 binding times the functional volume of the pancreas) was decreased by at least $40 \%$ in T1D. This study thus showed that PET quantification of BCM is feasible and that significant amounts of PET-measured $\mathrm{BCM}$ are present in T1D. Although the latter finding is consistent with the recent postmortem histochemical finding that a significant residual amount of BCM is still present in the pancreas of longstanding T1D patients, several potential limitations of this imaging approach need to be carefully evaluated.

\section{POTENTIAL LIMITATIONS}

As a trait marker of $\beta$-cells, VMAT2 must be specific for the islet $\beta$-cells within the pancreas (Fig. 3). VMAT2 immunofluorescent histochemical staining in the pancreas of humans and monkeys colocalized with islet $\beta$-cell insulin staining, and VMAT2 staining was absent from exocrine tissue (12). There was a strong correlation between the fractional pancreas area positive for islet insulin and VMAT2 in pancreata of healthy controls, T2D patients, and long-standing T1D patients (22). However, not all VMAT2 immunoreactivity was associated with $\beta$-cells. From the studies of human pancreas sections, filamentous VMAT2 staining can sometimes be found, presumably representing autonomic innervation (22). However, the total area of these structures is not significant $(<0.1 \%)$, relative to the area of VMAT2 staining associated with $\beta$-cells. 


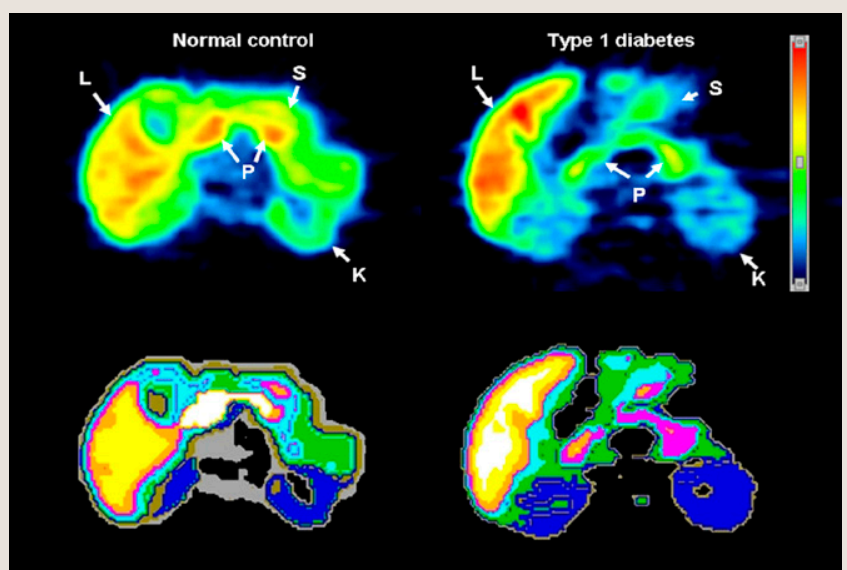

FIGURE 2. Transverse ${ }^{11} \mathrm{C}-\mathrm{DTBZ}$ PET images of healthy control (left) and T1D patient (right). Summed dynamic PET images were obtained 0-90 min after tracer injection of 500 MBq (top). Corresponding tissue segmentation images are also shown (bottom), with different colors representing different organs. $\mathrm{K}=$ kidney; $\mathrm{L}=$ liver; $\mathrm{P}=$ pancreas; $\mathrm{S}=$ stomach.

In addition, a small population of cells positive for pancreatic polypeptide (PPY) and VMAT2 was found in these studies. However, PPY cells account for less than $10 \%$ of the total $\beta$-cell population (23), and only 1 in 2 PPY cells was VMAT2positive. At least some PPY-positive/VMAT2-positive cells may represent committed progenitors of $\beta$-cells (24). It can be thus concluded that VMAT2 has a close relationship with BCM (i.e., insulin). However, VMAT2 expression is not completely restricted to $\beta$-cells, because small percentages of PPY cells, as well as the innervation, are VMAT2-positive.

Second, a potential limitation of BCM PET is its limited spatial resolution. $\beta$-cells are low in abundance $(1 \%-2 \%)$ and

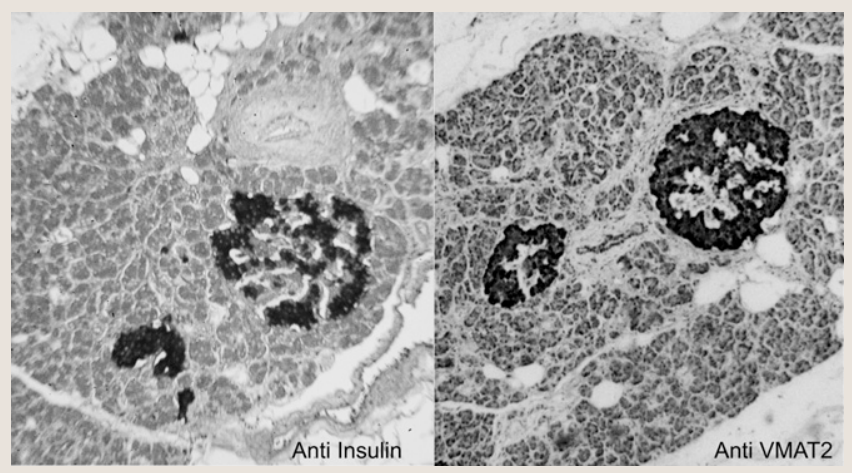

FIGURE 3. Sections of human pancreas stained with antiinsulin or anti-VMAT2 antibodies. Human islets of Langerhans are identified by reactivity with antiinsulin antibodies in sections of normal pancreas from cadaveric donor (left). Similar pattern of antibody staining is seen in adjacent section of pancreas from same donor reacted with anti-VMAT2 antibodies (right). Little reactivity is seen outside islet structures. Images were acquired at $\times 200$ magnification. are dispersed throughout the pancreas. However, PET appears excellent at detecting VMAT2 signal (Fig. 2). Our VMAT2 PET brain and pancreas imaging studies in baboons suggest that pancreatic VMAT2 binding is approximately $85 \%$ that of brain striatum.

In addition to detecting adequate VMAT2 signal, VMAT2 PET should allow accurate VMAT2 quantification in the pancreas. To estimate specific VMAT2 binding in the pancreas with ${ }^{11} \mathrm{C}$-DTBZ, the VMAT2-devoid renal cortex has been used as reference tissue for the estimation of nonspecific binding in the pancreas. Our group recently confirmed the validity of this approach in baboons (25). The accuracy of PET quantification of neuroreceptors (transporters) requires the availability of radioligands that satisfy certain conditions: good tissue uptake to allow high signal-to-noise ratios, high target affinity to allow high target (specific) signal, low nonspecific signal, and reversible specific binding for the kinetic modelbased quantification. Recently developed ${ }^{18} \mathrm{~F}-9$-fluoropropyl(+)-DTBZ (26) and other derivatives of DTBZ (27) attempt to improve some of the radioligand properties over ${ }^{11} \mathrm{C}$-DTBZ. Our group is currently evaluating ${ }^{18} \mathrm{~F}$-fluoropropyl-(+)-DTBZ PET in humans with T1D and T2D. Compared with ${ }^{11} \mathrm{C}$ DTBZ, ${ }^{18}$ F-fluoropropyl-(+)-DTBZ has higher affinity for VMAT2 and less lipophilicity and hence lower nonspecific binding. In addition, ${ }^{18} \mathrm{~F}$, with its longer physical half-life (110 $\mathrm{min})$, can make this radioligand more widely available.

Lastly, to monitor treatments that target $\beta$-cells, VMAT 2 must be a good state marker of viable $\beta$-cells. Animal studies suggest that VMAT2 binding measured by ${ }^{11} \mathrm{C}$-DTBZ PET appears to be a good state marker of BCM because VMAT2 binding decreased longitudinally with the decrease in the ability to clear glucose from the blood $(16,17)$. Although glucose concentrations can regulate insulin transcriptions $(28,29)$, our unpublished data suggest that VMAT2 expression is unaffected. Longitudinal human PET studies that address the issue of changes in the state of BCM are needed. Our preliminary human data with ${ }^{11} \mathrm{C}$ DTBZ suggest that the test-retest reproducibility of the quantification of VMAT2 is excellent. However, newer radioligands such as ${ }^{18} \mathrm{~F}$-fluoropropyl-(+)-DTBZ should improve the precision because of excellent signal-to-noise ratios.

\section{FUTURE DIRECTIONS}

As PET quantification of BCM with VMAT2 radioligands proceeds to critical validation studies in new-onset diabetes, other novel BCM targets and other imaging platforms for BCM quantification are emerging (30). One technique potentially applicable to human imaging may be manganese-enhanced MRI (31). This technique, rather than directly targeting $\beta$-cells, attempts to detect $\beta$-cell activation after enhanced intracellular $\mathrm{Mn}^{2+}$ mobilization via $\mathrm{Ca}^{2+}$ channels when $\beta$-cells are activated by glucose.

Currently, however, radionuclide-based imaging techniques appear most sensitive in directly targeting $\beta$-cells in humans. With the recognition that $\beta$-cells of the endocrine pancreas and neurons share the expression of several tissue-restricted transcripts (32), other opportunities to exploit PET tracers originally developed for quantification of targets in the brain 
present themselves for BCM imaging. These targets include dopamine $\mathrm{D}_{2}$ receptors (15) and L-3,4-dihydroxyphenylalanine (DOPA) decarboxylase (33). However, our preliminary results of imaging in the baboon pancreas with $\mathrm{D}_{2}$ tracers appear challenging. ${ }^{18} \mathrm{~F}-\mathrm{DOPA}$ appears useful only for congenital hyperinsulinism. Some groups are also exploiting widely available SPECT to image $\beta$-cell-specific targets such as the islet cell IC2 antigen and glucagonlike peptide-1 receptors using peptide agonists and antagonists labeled with ${ }^{111} \mathrm{In}$ or ${ }^{123}$ I $(34-36)$.

\section{CONCLUSION}

In diabetes, $\beta$-cells that exclusively secret insulin are lost. There is a growing need to develop biomarkers of $\beta$-cells, because therapeutic strategies are being developed that target $\beta$-cells. Radionuclide-based imaging using radioligands that directly target $\beta$-cells appear promising. In particular, VMAT2, which is adequately expressed and found in close association with insulin within the $\beta$-cells, can be quantified with PET in humans. However, these techniques are still in early stages, and careful further evaluations and technical developments are needed before they can be clinically used as a valid biomarker.

\section{ACKNOWLEDGMENTS}

This work was supported by the Leona M. and Harry B. Helmsley Charitable Trust; the PHS, NIH, NIDDK (DK077493); and JDRF International (37-2009-54).

\section{REFERENCES}

1. Meier JJ, Bhushan A, Butler AE, Rizza RA, Butler PC. Sustained beta cell apoptosis in patients with long-standing type 1 diabetes: indirect evidence for islet regeneration? Diabetologia. 2005;48:2221-2228.

2. Matveyenko AV, Butler PC. Relationship between beta-cell mass and diabetes onset. Diabetes Obes Metab. 2008;10(suppl 4):23-31.

3. Cowie CC, Rust KF, Ford ES, et al. Full accounting of diabetes and pre-diabetes in the U.S. population in 1988-1994 and 2005-2006. Diabetes Care. 2009;32:287-294.

4. Brandenburg D. History and diagnostic significance of C-peptide. Exp Diabetes Res. 2008:576862

5. Medvei VC. The History of Clinical Endocrinology. Carnforth, Lancashire, U.K.: Parthenon Publishing Group; 1993:16.

6. Medarova Z, Moore A. MRI as a tool to monitor islet transplantation. Nat Rev Endocrinol. 2009;5:444-452.

7. Shreve PD, Gross MD. Imaging of the pancreas and related diseases with PET carbon-11-acetate. J Nucl Med. 1997;38:1305-1310.

8. Toso C, Zaidi H, Morel P, et al. Positron-emission tomography imaging of early events after transplantation of islets of Langerhans. Transplantation. 2005;79:353-355.

9. Clark PB, Plaza MJ, Kraas J, et al. Dual radiotracer analysis of cholinergic neuronal changes in prediabetic mouse pancreas. Diabetes Technol Ther. 2009;11:107-111.

10. Maffei A, Harris PE. Targeting vesicular monoamine transporter type 2 for noninvasive PET-based $\beta$-cell mass measurements. Expert Rev Endocrinol Metab. 2007;2:35-46.

11. Koeppe RA, Frey KA, Vander Borght TM, et al. Kinetic evaluation of $\left[{ }^{11} \mathrm{C}\right]$ dihydrotetrabenazine by dynamic PET: measurement of vesicular monoamine transporter. J Cereb Blood Flow Metab. 1996;16:1288-1299.

12. Anlauf M, Eissele R, Schafer MK, et al. Expression of the two isoforms of the vesicular monoamine transporter (VMAT1 and VMAT2) in the endocrine pancreas and pancreatic endocrine tumors. J Histochem Cytochem. 2003;51: 1027-1040.

13. Ericson LE, Hakanson R, Lundquist I. Accumulation of dopamine in mouse pancreatic B-cells following injection of L-DOPA: localization to secretory granules and inhibition of insulin secretion. Diabetologia. 1977;13:117-124.

14. Raffo A, Hancock K, Polito T, et al. Role of vesicular monoamine transporter type 2 in rodent insulin secretion and glucose metabolism revealed by its specific antagonist tetrabenazine. J Endocrinol. 2008;198:41-49.

15. Rubi B, Ljubicic S, Pournourmohammadi S, et al. Dopamine D2-like receptors are expressed in pancreatic beta cells and mediate inhibition of insulin secretion. J Biol Chem. 2005;280:36824-36832.

16. Simpson NR, Souza F, Witkowski P, et al. Visualizing pancreatic beta-cell mass with [ ${ }^{11}$ C]DTBZ. Nucl Med Biol. 2006;33:855-864.

17. Souza F, Simpson N, Raffo A, et al. Longitudinal noninvasive PET-based beta cell mass estimates in a spontaneous diabetes rat model. J Clin Invest. 2006;116: 1506-1513.

18. Cline G, Carson RE, Ding YS, et al. Islet-selectivity of G-protein coupled receptor (GPCR) ligands evaluated for PET imaging [abstract]. Diabetes. 2008;58(suppl): 156 .

19. Kung M, Lieberman B, Hou C, et al. F-18(+)FP-DTBZ: an investigational PET ligand for measuring beta cell mass in the pancreas [abstract]. $\mathrm{J}$ Nucl Med. 2007;48(suppl):114P

20. Singhal T, Labaree D, Ropchan J, et al. Evaluation of [C-11]DTBZ-PET for estimation of pancreatic beta cell mass (BCM) in a rat model of diabetes [abstract]. J Nucl Med. 2008;49(suppl):317P.

21. Goland R, Freeby M, Parsey R, et al. ${ }^{11} \mathrm{C}$-dihydrotetrabenazine PET of the pancreas in subjects with long-standing type 1 diabetes and in healthy controls. J Nucl Med. 2009;50:382-389.

22. Saisho Y, Harris PE, Butler AE, et al. Relationship between pancreatic vesicular monoamine transporter 2 (VMAT2) and insulin expression in human pancreas. J Mol Histol. 2008;39:543-551.

23. Rahier J, Goebbels RM, Henquin JC. Cellular composition of the human diabetic pancreas. Diabetologia. 1983;24:366-371.

24. Herrera PL. Defining the cell lineages of the islets of Langerhans using transgenic mice. Int J Dev Biol. 2002;46:97-103.

25. Ichise M, Slifstein M, Easwaramoorthy B, et al. VMAT2 imaging of baboons with two ${ }^{18}$ F-FP-DTBZ enantiomers [abstract]. J Nucl Med. 2009;50(suppl): 227P.

26. Goswami R, Ponde DE, Kung MP, Hou C, Kilbourn MR, Kung HF. Fluoroalkyl derivatives of dihydrotetrabenazine as positron emission tomography imaging agents targeting vesicular monoamine transporters. Nucl Med Biol. 2006;33: 685-694.

27. Kung HF, Lieberman BP, Zhuang ZP, et al. In vivo imaging of vesicular monoamine transporter 2 in pancreas using an ${ }^{18} \mathrm{~F}$ epoxide derivative of tetrabenazine. Nucl Med Biol. 2008;35:825-837.

28. Goodison S, Kenna S, Ashcroft SJ. Control of insulin gene expression by glucose. Biochem J. 1992;285:563-568.

29. Wang H, Kouri G, Wollheim CB. ER stress and SREBP-1 activation are implicated in beta-cell glucolipotoxicity. J Cell Sci. 2005;118:3905-3915.

30. Moore A. Advances in beta-cell imaging. Eur J Radiol. 2009;70:254-257.

31. Antkowiak PF, Tersey SA, Carter JD, et al. Noninvasive assessment of pancreatic beta-cell function in vivo with manganese-enhanced magnetic resonance imaging. Am J Physiol Endocrinol Metab. 2009;296:E573-E578.

32. Maffei A, Liu Z, Witkowski P, et al. Identification of tissue-restricted transcripts in human islets. Endocrinology. 2004;145:4513-4521.

33. Mohnike K, Blankenstein O, Minn H, Mohnike W, Fuchtner F, Otonkoski T. $\left[{ }^{18} \mathrm{~F}\right]-\mathrm{DOPA}$ positron emission tomography for preoperative localization in congenital hyperinsulinism. Horm Res. 2008;70:65-72.

34. Moore A, Bonner-Weir S, Weissleder R. Noninvasive in vivo measurement of beta-cell mass in mouse model of diabetes. Diabetes. 2001;50:22312236.

35. Gotthardt M, Lalyko G, van Eerd-Vismale J, et al. A new technique for in vivo imaging of specific GLP-1 binding sites: first results in small rodents. Regul Pept. 2006;137:162-167.

36. Mukai E, Toyoda K, Kimura H, et al. GLP-1 receptor antagonist as a potential probe for pancreatic beta-cell imaging. Biochem Biophys Res Commun. 2009;389:523-526. 